\title{
Qualitative and Quantitative Workplace Analysis of Staff Requirement in an Academic Radiology Department
}

\section{Qualitative und quantitative Arbeitsplatzanalyse zur Ermittlung des Personalbedarfs in einer universitären radiologischen Abteilung}

Authors

Ulrike Streit, Johannes Uhlig, Joachim Lotz, Babak Panahi, Ali Seif Amir Hosseini

Affiliation

Radiology, University Medical Center Göttingen Institute for Diagnostic and Interventional Radiology, Göttingen, Germany

Key words

health policy and practice, MR-imaging, decision analysis

received 16.07 .2020

accepted 17.03.2021

published online 27.05.2021

Bibliography

Fortschr Röntgenstr 2021; 193: 1277-1283

DOI 10.1055/a-1472-6530

ISSN 1438-9029

(C) 2021. Thieme. All rights reserved.

Georg Thieme Verlag KG, Rüdigerstraße 14,

70469 Stuttgart, Germany

Correspondence

Dr. Ali Seif Amir Hosseini

Universitätsmedizin Göttingen, Institut für Diagnostische und Interventionelle Radiologie, Robert-Koch-Straße 40, 37075 Göttingen, Germany

ali.seif@med.uni-goettingen.de

\section{ABSTRACT}

Purpose The role of today's hospital-based radiologists goes far beyond interpretation-related tasks. This observational study defines these types of activities and quantifies the type of value-adding interactions radiologists experience on a daily basis with referring departments and other health personnel. The purpose of this study is to evaluate the quality and quantity of these value-adding non-image interpretation tasks in the daily routine of hospital-based residents and attending radiologists.

Methods A prospective, observational study was performed in the radiology department of a German university hospital. Two experienced radiologists performed a 30-day observation of the entire medical staff. The observers followed the subject radiologists throughout the workday, recording activities using a time and motion methodology. An evaluation matrix was developed to characterize and quantify image interpretation tasks (IITs), non-image interpretation tasks (NITs), and contingency allowance (CA) for residents and attending radiologists. Here, the example of the MRI unit is used.

Results Four main categories of responsibilities for NITs were identified including teaching and education, clinical decision support, management and organization, and patient care. The quantitative analysis for residents showed: IITs $15 \mathrm{~h} / \mathrm{d}$ (53\%), NITs 9.8 h/d (34\%), CA $2.2 \mathrm{~h} / \mathrm{d}$ (13\%). For attendings the analysis revealed: IITs $6.7 \mathrm{~h} / \mathrm{d}(40 \%)$, NITs $7.8 \mathrm{~h} / \mathrm{d}(47 \%)$, and CA $1.7 \mathrm{~h} / \mathrm{d}(13 \%)$. This resulted in staff requirements of 2 attendings and 3.4 residents for the MRI unit. On average, $6 \mathrm{TSEs} / \mathrm{h}$ occurred in the case of residents and $13 \mathrm{TSEs} / \mathrm{h}$ in the case of attendings.

Conclusion NITs consumed a significant portion of a radiologist's workday. Therefore, the number of examinations performed is not a reliable surrogate for the daily workload of hospital-based radiologists especially in cross-sectional imaging units. Though time-consuming, these non-interpretive tasks are greatly contributing to the fact that modern radiology is assuming a central position in patient management, fulfilling a critical role that surpasses image interpretation-related tasks to include a more integrative and consultative role. These findings will help to further define the changing role of radiologists with respect to other physicians, non-medical personnel, hospital administrators, as well as policy makers.

Key points:

- Staff requirements are a significant factor in department strategy.

- Targeted analysis can deliver valuable information about workload per activity and the required staff.

- The number of examinations performed is not a reliable surrogate for the daily workload of hospital-based radiologists.

- NITs comprise a significant portion of a radiologist's workday.

- Though time-consuming, non-interpretive tasks contribute to the fact that modern radiology is assuming a central role in patient management.

\section{Citation Format}

- Streit U, Uhlig J, Lotz J et al. Qualitative and Quantitative Workplace Analysis of Staff Requirement in an Academic Radiology Department. Fortschr Röntgenstr 2021; 193: $1277-1283$ 


\section{ZUSAMMENFASSUNG}

Ziel Das Aufgabenprofil von heutigen Radiologen wird immer vielseitiger und geht über die reine Bildinterpretation und -befundung hinaus. Ziel dieser Beobachtungsstudie war es, mithilfe einer qualitativen und quantitativen Arbeitsplatzanalyse angepasste radiologische Tätigkeitsprofile zu ermitteln und hieraus den tatsächlichen Personalbedarf einer universitären radiologischen Abteilung abzuleiten.

Material und Methoden Im Rahmen einer Qualitätsinitiative wurde eine prospektive Beobachtungsstudie an einer deutschen Universitätsklinik durchgeführt. Zwei erfahrene Radiologen führten über 30 Tage eine qualitative und quantitative Arbeitsplatzanalyse durch. Dabei wurde das ärztliche Personal im Alltag begleitet und interpretative Tätigkeiten (IITs) und nichtinterpretative Tätigkeiten (NITs) von Assistenzärzten und Oberärzten dokumentiert unter Anwendung von Zeitund Bewegungsanalysen sowie Experteninterviews. Ferner wurden Wechselereignisse (TSEs) zwischen NITs und IITs erfasst. Hier wurde das Beispiel der MRT-Funktionseinheit gewählt.
Ergebnisse Die qualitative Arbeitsplatzanalyse der Funktionseinheit MRT ergab eine Tätigkeitsmatrix mit den übergeordneten Kategorien IIT und NIT und Verteilzeitfaktor (VZ). Ferner ließen sich die NITs in 4 Subkategorien unterteilen: Management und Organisation, Patientenbetreuung, Clinical Decision Support, Ausbildung. Die quantitative Analyse ergab folgenden Zeitaufwand bei Assistenzärzten: IITs $15 \mathrm{~h} / \mathrm{d}$ (53\%), NITs 9,8 h/d (34\%), VZ 3,7 h/d (13\%). Für Oberärzte ergaben sich folgende Messungen: IITs 6,7 h/d (40\%), NITs 7,8 h/d (47\%), VZ 1,2 h/d (13\%). Insgesamt wurde ein Personalbedarf von 2 Vollzeitkräften an Oberärzten und 3,4 Vollzeitkräften an Assistentsärzten für die Funktionseinheit MRT berechnet. Bei Assistenzärzten wurden durchschnittlich 6 TSEs/h und bei Oberärzten 13 TSEs/h beobachtet.

Schlussfolgerung NITs machen einen signifikanten Anteil des radiologischen Alltags aus, daher sind Kennzahlen wie Untersuchungen pro Tag allein nicht repräsentativ für die tägliche Arbeitslast eines Radiologen im Krankenhausbetrieb. Obwohl sie zeitintensiv und disruptiv sind, tragen NITs in erheblichem Maße dazu bei, dass der moderne Radiologe eine zentrale Rolle im Management von Patienten einnimmt.

\section{Introduction}

Modern university radiology departments are an increasingly complex work environment with a continually increasing number of patients and examinations [1, 2]. As an example, the Annual Imaging and Radiodiagnostics Data from the National Health System (NHS) show this drastic development since 1995 in Great Britain. The data show an average annual growth of all imaging methods of $3.4 \%$, which corresponds to an increase of $40 \%$ in 10 years. Stratified by modality, the data show disproportionately large growth of cross-sectional imaging with an average annual growth of $10.1 \%$ for CT examinations and $12.3 \%$ for MRI examinations, corresponding to an increase in examination volume of $160 \%$ for CT and $220 \%$ for MRI in the period between 2004 and 2014 [3].

However, in addition to the resulting increase in workload, the classic job profile of radiologists is also evolving [4, 5]. Radiology is increasingly becoming the interface for the management of the diagnostic workup and information between clinical departments. In addition to traditional tasks, like image interpretation and interventions, "clinical radiologists" are expected to perform new activities and assume new responsibilities, e. g. increased interaction with patients and referring physicians [6]. Moreover, the demand for radiology services is increasing. For example, a significant amount of time in the daily routine in radiology is spent preparing for and attending interdisciplinary tumor boards and performing follow-up activities. The interpretation of increasingly comprehensive examinations is also becoming more challenging due to technical innovations and the introduction of complex structured reporting, for example, for oncological or cardiovascular diseases. These new responsibilities and tasks resulting from technological advances have created in an imbalance between staffing and actual personnel requirements even when using new software and professional PACS systems to manage the large number of examinations.

Despite their heterogeneity, these tasks and responsibilities can be largely divided into two categories, image interpretation tasks (IITs) and non-image interpretation tasks (NITs) [2, 7]. IITs include classic radiology tasks like the evaluation and interpretation of radiology examinations. NITs are significantly more diverse and more difficult to plan and predict. The time requirement for NITs is often overlooked in planning and organization. NITs comprise tasks like case conferences, telephone calls and case discussions with referring physicians, discussions with patients, and organizational tasks like scheduling, training residents, etc. Differentiation of these tasks is relevant for a personnel requirements analysis because the work required for IITs correlates directly with the number of examinations performed, while a different empirical measurement for tasks must be selected for NITs.

However, at present, strategic personnel management in health care, particularly in hospitals, has not been sufficiently implemented [8]. A targeted personnel requirements analysis can provide valuable information about the work and personnel required for each task. As part of a quality initiative for process evaluation and optimization at our institute, a qualitative and quantitative personnel requirements analysis for physicians was performed. In the following we present the results of our analysis for the MRI unit.

\section{Methods}

As part of a quality initiative for all radiology units, the Institute for Diagnostic and Interventional Radiology at University Hospital Göttingen prospectively determined the actual staff requirements 
for residents and attending physicians within a 30-day period based on a qualitative and quantitative workplace analysis. The present study is based on the MRI unit, which includes two $1.5 \mathrm{~T}$ scanners operated from 8:15 am to 5:15 pm Monday through Friday with a weekly working time for physicians of 42 hours. All data were collected and evaluated by two experienced radiologists.

As a rule, the goal of a personnel requirements analysis is to determine the number of employees needed to meet the demands of existing organizational structures. Personnel requirements for covering absences due to vacations, illness, training, etc. are also determined. Various calculation methods are available. There are simple estimation methods and methods based on metrics. Recognized estimation methods include expert estimates and motion and time studies [9, 10]. The presented analysis included a qualitative and a quantitative portion.

\section{Qualitative analysis}

Qualitative workplace analyses are used to create respective requirement profiles. The structural organization, i.e., the structure of a physician's workplace within the MRI unit, was used for this in a first step. A complete list of all radiology tasks in the unit was first made with the goal of identifying the basic tasks of particular physicians with a high and measurable level of granularity and to use this information to create task profiles for every workplace in the unit under consideration of the necessary degree of qualification (specialist/attending physician or resident). The basic tasks of attending physicians and residents were assigned to the categories IIT and NIT. The NITs were then divided into subcategories based on the type of task (see below). Categorization of tasks is important because time requirements are calculated differently in the quantitative part of the analysis.

\section{Quantitative analysis}

For the quantitative analysis detailed metrics were used, which is a generally recognized methodology. Consequently, it was possible to determine the time needed for individual procedures based on the number of examinations performed. $[9,10]$. Detailed metrics were used to calculate IITs. We used the number of MRI examination performed here. The time needed for each work step was measured on the basis of structured self-documentation by attending physicians and residents as well as by observations [9, 10].

However, measuring tasks based on the number of examinations performed only includes IITs. Therefore, the total workload was underestimated since the time required for NITs is not included. The time required for individual NITs was estimated based on employee interviews at each workplace and selective time measurements over a period of 30 days.

Tasks that cannot be classified as IIT or NIT are considered contingency allowance. This is a correction factor that takes tasks that delay or hinder the production process (e.g., the process of image interpretation) into consideration, e. g., time to recover from fatigue, time for presentations, time for continuing education, time off, etc. These times are calculated with a fixed percentage of the daily working time. As a rule, this correction factor is $10-15 \%$ depending on the workplace and the professional group $[9,10]$. In our analysis a contingency allowance of $15 \%$ of the total
NITs and IITs was used. The personnel requirements per workplace for residents and attending physicians (IITs and NITs) were then calculated based on the formulas listed in > Fig. 2 .

Due to the fundamentally different nature of IITs and NITs, switching between the two disrupts the workflow. These task switching events (TSEs) are therefore disruptive and were taken into consideration in the analysis [7]. The average number of task switching tasks per hour for both residents and attending physicians in the MRI unit was observed.

\section{Data analysis}

An individual requirement profile was created for every radiology workplace based on the qualitative analysis. The data were collected and evaluated using Microsoft Excel Version 14.6 (Microsoft Corporation, Redmond, Washington). The activity times were compiled for every task and task group (NIT and IIT) and averages for the entire observation period were calculated.

\section{Results}

\section{Qualitative analysis}

This analysis resulted in a workplace evaluation matrix for every unit of the department. The task profiles could be adjusted for all units and for each task performed by attending physicians and residents (see $>$ Fig. 1). Four NIT subcategories were identified: management and organization, patient care, clinical decision support, and training. The contingency allowance category includes various additional tasks, such as continuing medical education, preparation of presentations, as well as a factor typically used in personnel management, which allows for forgotten tasks, secondary tasks, and recovery, e. g., from work at a workstation. Finally, this category includes tasks that are not clearly associated with a workplace but are required for every physician in the daily routine (see method section).

\section{Quantitative analysis}

The task profiles of the qualitative analysis provide the basis for the personnel requirement calculation in a further step. The evaluation of the number of examinations performed yielded the average number of MRI examinations per day. Based on the number of examinations and the measured average time for image interpretation, discussion, and correction, a cumulative workload (IITs) for all residents of 15 hours per day (approximately $53 \%$ of the total workload) was calculated. For attending physicians, this value was 6.7 hours (IITs), which corresponds to approx. $40 \%$ of the total workload. The time required for NITs was significantly higher among attending physicians (7.8 hours) and comprised $47 \%$ of the total workload. Residents performed more IITs than NITs (53\% vs. $34 \%$ ). The contingency allowance category comprised $13 \%$ of the total workload among residents and attending physicians (this corresponds to total NITs and IITs multiplied by 0.15 or $15 \%)$. In total, this resulted in a contingency allowance of 2 for attending physicians and 3.4 for residents for the MRI unit (see $>$ Table 1, 2). 


$$
\mathrm{PB}=\frac{\sum_{\mathrm{i}=1}^{\mathrm{n}} m(I I T)_{i} t_{i}+m(N I T)_{i} t_{i}+\mathrm{VZ}}{\mathrm{T}}
$$

$\begin{array}{ll}\mathrm{PB} & = \\ \mathrm{i} & = \\ \mathrm{m}(\mathrm{IIT})_{\mathrm{i}} & = \\ \mathrm{m}(\mathrm{NIT})_{\mathrm{i}} & = \\ \mathrm{t}_{\mathrm{i}} & = \\ \mathrm{T} & = \\ \mathrm{VZ} & =\end{array}$

Personalbedarf

Tätigkeiten einer spezifischen Kategorie

Anzahl der zu bearbeitenden gleichartigen Tätigkeiten der Kategorie i während des Messzeitraums

Anzahl der zu bearbeitenden gleichartigen Tätigkeiten der Kategorie i während des Messzeitraums

durchschnittliche Bearbeitungszeit für eine Tätigkeit der Kategorie i, wobei i =1, 2,

$$
\ldots, \mathrm{n}
$$

42 Stunden Wochenarbeitszeit laut Arbeitsvertrag im Messzeitraum

Verteilzeitfaktor ( $15 \%$ der Summe aus NITs und IITs):

Faktoren, die die Produktion verhindern oder verzögern. Hierbei handelt es sich um einen Korrekturfaktor der reinen Arbeitszeit, der folgende zusätzliche Zeitaufwendungen berücksichtigt:

- Zeit für weitere fachspezifische Nebentätigkeiten, die nicht als NIT gelten

- Abwesenheiten vom Arbeitsplatz

- Zeit für Erholung aufgrund der Ermüdung durch Arbeitserledigung

- Vorbereiten von Vorträgen

- Persönliche Weiterbildung

* Zeit für Lehre und Forschung in dieser Berechnung nicht berücksichtigt

- Fig. 1 Formula for determining gross personnel requirements (target number of employees).

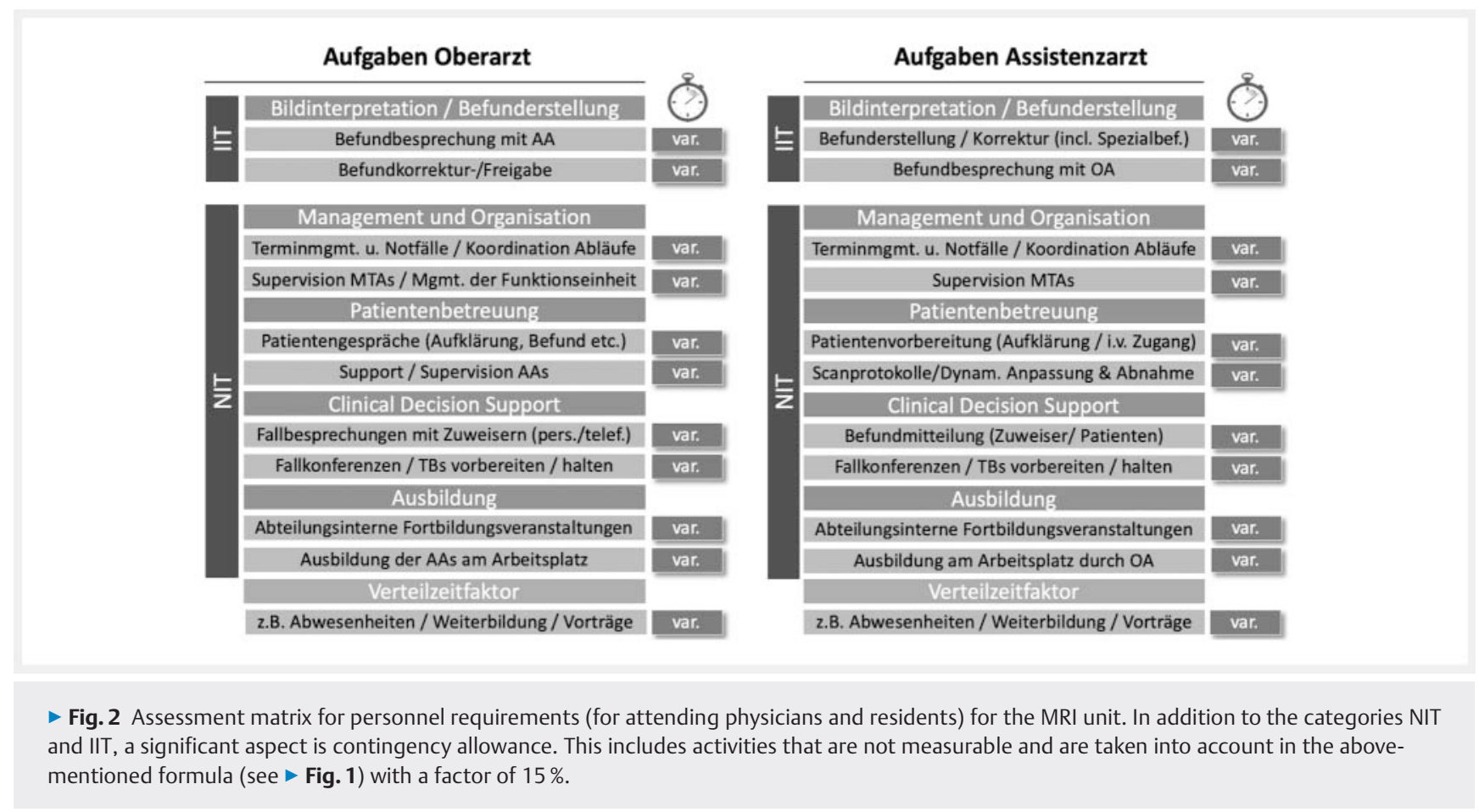

The switch between NITs and IITs was recorded in a further step. During the observation period, 5 TSEs per hour for residents and 8 TSEs per hour for attending physicians were seen on average.

\section{Discussion}

The modern radiology department is highly complex and includes many disruptors $[2,11]$. In addition, a significant increase in the number of examinations must be expected in the coming years, particularly in the cross-sectional imaging sector [3]. To take these challenges into consideration, personnel planning must be performed in a future-oriented manner. In many departments the staffing ratio is based on traditional hierarchies and established structures and not on optimally structured workflows. Therefore, it is extremely important to regularly ensure that staffing information is up-to-date and to determine the actual personnel requirements. The goal of the study was to use work science methods adapted to personnel requirement calculation for the daily routine in radiology. 
- Table 1 Activity profile of residents in the MRI unit with calculation of the actual personnel requirements per day in minutes depending on examination numbers. The list shows the results of an analysis after complete deconstruction of the radiological activities in order to identify the basic tasks of residents in the MRI unit. The data reveals clear distribution in favor of image interpretation tasks (52\%) compared to non-image interpretation tasks (34\%) with a total daily working time of 28.6 hours, which corresponds to a staff requirement of 3.4 full-time equivalent (FTE). Contingency allowance (CA) accounts for $13 \%$ of the total working day excluding breaks.

\begin{tabular}{|c|c|c|c|}
\hline & tasks & $\begin{array}{l}\text { cumulative time } \\
\text { per task in } \\
\text { minutes per day }\end{array}$ & $\begin{array}{l}\text { total time in hours/ } \\
\text { percentage of the } \\
\text { total working time }\end{array}$ \\
\hline \multicolumn{4}{|c|}{ IIT (image interpretation task) } \\
\hline \multicolumn{4}{|c|}{$\begin{array}{l}\text { image interpretation/reporting of } \\
\text { findings }\end{array}$} \\
\hline & reporting of findings/correction & $660 \mathrm{~min}$ & \\
\hline & case discussion with attending physician & $240 \mathrm{~min}$ & \\
\hline & & & 15 hours (53\%) \\
\hline \multicolumn{4}{|c|}{$\begin{array}{l}\text { NIT (non-image interpretation } \\
\text { tasks) }\end{array}$} \\
\hline \multicolumn{4}{|c|}{ management and organization } \\
\hline & appointment management and emergencies & $30 \mathrm{~min}$ & \\
\hline & supervision of radiologic technologists & $20 \mathrm{~min}$ & \\
\hline \multirow[t]{2}{*}{ patient care } & $\begin{array}{l}\text { patient preparation } \\
\text { (informed consent/i.v. access) }\end{array}$ & $102 \mathrm{~min}$ & \\
\hline & scan protocols/dynamic adjustment \& acceptance & $70 \mathrm{~min}$ & \\
\hline \multirow[t]{2}{*}{ clinical decision support } & $\begin{array}{l}\text { communication of findings } \\
\text { (referring physician/patient) }\end{array}$ & $30 \mathrm{~min}$ & \\
\hline & $\begin{array}{l}\text { case conferences/tumor boards as well as } \\
\text { preparation/follow-up }\end{array}$ & $188 \mathrm{~min}$ & \\
\hline \multirow[t]{3}{*}{ training } & internal continuing education & $60 \mathrm{~min}$ & \\
\hline & workplace training by attending physician & $90 \mathrm{~min}$ & \\
\hline & & & 9.8 hours (34\%) \\
\hline \multicolumn{4}{|l|}{ contingency allowance } \\
\hline & $\begin{array}{l}\text { for example, absences/continuing education/ } \\
\text { presentations }\end{array}$ & $223 \mathrm{~min}$ & \\
\hline & & & 3.7 hours (13\%) \\
\hline & & & 28.6 hours \\
\hline & & & 3.4 full-time equivalent \\
\hline
\end{tabular}

In recent years various factors have contributed to the fact that the value added chain in radiology has changed significantly [6]. In addition to challenging interpretive tasks whose time requirement correlates directly with the number of examinations performed, non-interpretive tasks are assuming an increasingly important role in the daily routine in radiology. Our data shows that these NITS already make up the majority of tasks particularly in the case of attending physicians. Our results are consistent with the data of other studies assigning NITs a similar level of relevance $[2,7,12$, 13]. Non-interpretive tasks are increasingly defining the self-image of the modern radiologist, who as a clinical partner for referring physicians plays a key role in the diagnosis, information management, and treatment of patients, resulting in significant added value. Therefore, this percentage of the daily routine must also be taken into consideration in personnel requirements calculations.
In spite of their relevance for the occupational profile of radiologists, NITs are disruptive and difficult to plan. NITs can greatly disrupt the workflow of classic interpretive tasks, i. e., interpretation, discussion, and validation of findings, which require quiet and concentration, and this can potentially lead to a loss of quality. Frequent switching between IITs and NITs results in inefficiencies [13].

The study by Lee et al. was able to show that repetitive task switching events between IITs and NITs cause significant disruptions in the daily routine in radiology resulting in a significantly longer time requirement for IITs. They recommend a separation of dedicated IIT and NIT workflows [2]. Blaint et al. showed in their study that frequent phone calls have a negative effect on the quality of findings [14]. This weak point in the daily routine in radiology requires more attention. This issue cannot be simply resolved with more personnel. Instead, the processes in the units 
- Table 2 Activity profile of attending physicians in the MRI unit with calculation of the actual personnel requirements per day in minutes depending on number of examinations. The list shows the results of an analysis after complete deconstruction of the radiological activities in order to identify the basic tasks of attending physicians in the MRI unit. In this case, the data reveals a distribution in favor of non-image interpretation tasks with $48 \%$ compared to $41 \%$ for image interpretation tasks with a total working time of 16.2 hours per day. Correlated with examination numbers, this corresponds to a staff requirement of 2 FTE attending physicians. Contingency allowance (CA) accounts for approximately $10 \%$ of the total working day excluding breaks.

\begin{tabular}{|c|c|c|c|}
\hline & tasks & $\begin{array}{l}\text { cumulative time } \\
\text { per task in } \\
\text { minutes per day }\end{array}$ & $\begin{array}{l}\text { total time in hours/ } \\
\text { percentage of the } \\
\text { total working time }\end{array}$ \\
\hline \multicolumn{4}{|c|}{ IIT (image interpretation task) } \\
\hline \multicolumn{4}{|c|}{$\begin{array}{l}\text { image interpretation/reporting of } \\
\text { findings }\end{array}$} \\
\hline & case discussion with resident & $240 \mathrm{~min}$ & \\
\hline & correction/release of findings & $160 \mathrm{~min}$ & \\
\hline & & & 6.7 hours ( $40 \%)$ \\
\hline \multicolumn{4}{|c|}{$\begin{array}{l}\text { NIT (non-image interpretation } \\
\text { tasks) }\end{array}$} \\
\hline \multicolumn{4}{|c|}{ management and organization } \\
\hline & appointment management and emergencies & $60 \mathrm{~min}$ & \\
\hline & $\begin{array}{l}\text { supervision of radiologic technologists/ } \\
\text { management of the unit }\end{array}$ & $30 \mathrm{~min}$ & \\
\hline \multirow[t]{2}{*}{ patient care } & $\begin{array}{l}\text { patient discussions } \\
\text { (informed consent/discussion of findings, etc.) }\end{array}$ & $15 \mathrm{~min}$ & \\
\hline & Support/supervision of residents & $20 \mathrm{~min}$ & \\
\hline \multirow[t]{2}{*}{ clinical decision support } & $\begin{array}{l}\text { case discussions with referring physicians } \\
\text { (in person/via telephone) }\end{array}$ & $70 \mathrm{~min}$ & \\
\hline & $\begin{array}{l}\text { preparation/holding of case conferences/tumor } \\
\text { boards }\end{array}$ & $195 \mathrm{~min}$ & \\
\hline \multirow[t]{3}{*}{ training } & internal continuing education & $40 \mathrm{~min}$ & \\
\hline & workplace training of residents & $40 \mathrm{~min}$ & \\
\hline & & & 7.8 hours $(47 \%)$ \\
\hline \multicolumn{4}{|l|}{ contingency allowance } \\
\hline & $\begin{array}{l}\text { for example, absences/continuing education/ } \\
\text { presentations }\end{array}$ & $131 \mathrm{~min}$ & \\
\hline & & & 2.2 hours $(13 \%)$ \\
\hline & & & 25.6 hours \\
\hline & & & 2.0 full-time equiva \\
\hline
\end{tabular}

of a radiology department must be fundamentally reconsidered. The goal should be to minimize the effect of TSEs so that processes can occur without inefficiencies to the greatest extent possible. As a result of strict organization of the work environment for interpreting radiologists, an optimal workflow for the interpretation process can be achieved [15]. The insight provided by our study resulted in adjustments to the internal workflows in the MRI unit. For example, a new telephone number for all questions from referring physicians was set up in the modality. One person was assigned on an alternating basis to answer questions from referring physicians. A clear structure for patient preparation and informed consent was also defined in order to minimize the effect of TSEs on the interpretation process. Residents then acted as the contact person for referring physicians and patients in the unit on a rotating basis with the positive effect that interpreting physicians were able to work quietly and efficiently without having to constantly interrupt the workflow.

Therefore, the goal of a personnel requirements analysis should be not only to increase personnel but also to create awareness that in addition to the classic tasks performed by radiologists there are also a significant number of tasks that should also be taken into consideration in personnel requirements planning even though they are difficult to measure. In addition to an increase in the number of examinations performed, the number of NITs has increased significantly in recent years and they take up valuable working time due to their disruptive nature [13]. 
Given the fact that personnel costs are increasing and currently comprise up to $60 \%$ of the total costs of a hospital [16], a traceable and transparent personnel requirements analysis can be used to make a solid argument to hospital management for more personnel resources. The argument can be strengthened by additional process optimization recommendations. However, such recommendations must come from radiologists. Those outside of radiology do not have a proper understanding of the intricacies of the daily routine in radiology. Therefore, a personnel requirements calculation should come from the radiology department. For this reason, radiologists must give greater priority to organizational issues and personnel management in the future.

\section{Limitations}

The present study has some limitations. The lack of generalizability and transferability of institute-specific data to other radiology departments is an important limitation. Since every department has special features due to the particular conditions on-site, only cumulative data and not individual times, e. g., "minutes per finding" or "minutes per case discussion" were included in the present study. The goal of the study was to develop a matrix that can be generalized so that the method can be adapted to individual needs and used accordingly. In principle, it can be transferred to any university or non-university radiology facility.

A further limitation is the analysis of task switching events (TSEs) between interpretive and non-interpretive tasks. Although it was possible to determine the quantity of TSEs, their actual effect on daily work is difficult to measure.

There are also further potential limitations regarding internal validity that must be taken into consideration in all empirical real-time analyses.

A potential limitation is that the study period is not representative for decisions at a later point in time. This was counteracted by using averages for the daily number of examinations performed in order to compensate for fluctuations. Moreover, we selected an examination period that did not include any extraordinary circumstances, e. g., vacations, conventions, or other relevant absences of physicians.

A further potential limitation is variations in the level of training of the residents and attending physicians participating in the study since this ultimately affects the number of images interpreted per day and the number of questions residents ask the attending physician. However, an adequate representation of the groups of physicians was able to be achieved.

A final possible limitation of the internal validity is the Hawthorne Effect $[17,18]$. This effect has been described in sociology and psychology and can occur in group-based observational studies. It refers to a tendency of study participants to adjust their natural behavior because they know they are participating in a study and are being observed. To account for a possible data bias due to the Hawthorne Effect, all participants were included early in the design and implementation of the study and informed of the strict anonymization of the data.

Personnel management is a dynamic process. The advantage of the motion matrix presented here is that it can be used to also simulate future developments within the department or the hos- pital, e.g., a further increase in the number of examinations or a slightly shorter length of hospitalization resulting in higher organizational pressure and higher patient numbers in case conferences. Trends in a hospital can thus be taken into consideration and accounted for with corresponding personnel planning. In addition to sufficiently robust staffing, comprehensive strategic personnel management also includes efficient assignment of personnel with the goal of better utilizing the available pool of skills and labor. This can contribute to an increase in efficiency and quality assurance in every department and ultimately the entire hospital.

\section{Conflict of Interest}

The authors declare that they have no conflict of interest.

\section{References}

[1] Health at a Glance 2015: OECD; 2015

[2] Lee MH, Schemmel AJ, Pooler BD et al. Radiology Workflow Dynamics: How Workflow Patterns Impact Radiologist Perceptions of Workplace Satisfaction. Acad Radiol 2017; 24: 483-487

[3] Services NEA. NHS Imaging and Radiodiagnostic activity. In 2014

[4] Brady AP. Measuring Consultant Radiologist workload: method and results from a national survey. Insights Imaging 2011; 2: 247-260

[5] MacDonald SL, Cowan IA, Floyd R et al. Measuring and managing radiologist workload: application of lean and constraint theories and production planning principles to planning radiology services in a major tertiary hospital. J Med Imaging Radiat Oncol 2013; 57: 544-550

[6] Enzmann DR. Radiology's value chain. Radiology 2012; 263: 243-252

[7] Schemmel A, Lee M, Hanley T et al. Radiology Workflow Disruptors: A Detailed Analysis. J Am Coll Radiol 2016; 13: 1210-1214

[8] Busse R, Schreyögg J, Stargardt T. Management im Gesundheitswesen; 2013

[9] Lindner-Lohmann D, Lohmann F, Schirmer U. Personalmanagement; Springer; 2016

[10] Thommen J-P, Achleitner A-K, Gilbert DU et al. Allgemeine Betriebswirtschaftslehre; Springer; 2016

[11] Yu JP, Kansagra AP, Mongan J. The radiologist's workflow environment: evaluation of disruptors and potential implications. J Am Coll Radiol 2014; 11: 589-593

[12] Dhanoa D, Dhesi TS, Burton KR et al. The evolving role of the radiologist: the Vancouver workload utilization evaluation study. J Am Coll Radiol 2013; 10: 764-769

[13] Kansagra AP, Liu K, Yu JP. Disruption of Radiologist Workflow. Curr Probl Diagn Radiol 2016; 45: 101-106

[14] Balint BJ, Steenburg SD, Lin $\mathrm{H}$ et al. Do telephone call interruptions have an impact on radiology resident diagnostic accuracy? Acad Radiol 2014; 21: $1623-1628$

[15] Grupp U, Maurer M. [Improvement of the processes around the radiology workplace: avoidance of time delays]. Radiologe 2014; 54: 27-31

[16] Wolff ], Auber G, Schober T et al. Arbeitszeitverteilung von Ärzten in einem deutschen Universitätsklinikum. Dtsch Arztebl International 2017; 114: 705-711

[17] Hart CWM. The Hawthorne Experiments. The Canadian Journal of Economics and Political Science/Revue canadienne d'Economique et de Science politique 1943; 9: 150-163

[18] Parsons HM. What Happened at Hawthorne? Science 1974; 183: 922 